\title{
Salon
}

\section{CMAf's Salon: lateral thinking about health}

Salon: a gathering of stimulating people under the roof of an inspiring hostess, partly to amuse one another and partly to refine their taste and increase their knowledge through conversation and reading (Wikipedia).

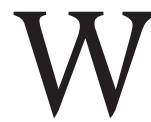
elcome to CMAJ Salon, an exchange of lateral thinking about health that aspires to feed the culture of curiosity and nurture the intellect, both in print and online.

Salons began in Renaissance Italy and France but gained prominence for stimulating lively intellectual conversation in I7th-century France. Initially, salons were concerned with the fields of arts and literature, but later they expanded to include music, philosophy and politics. Now, CMAPs Salon introduces health as the overarching topic of discourse. Health, in this context, will be interpreted in the widest manner possible with potential subjects ranging from an ode to your favourite body part to shrinking our environmental footprint, from an exposition on the stethoscope to innovative cognitive theories.

CMAF's Salon will be an exploration of a nascent idea or hypothesis that is fuelled by fact and driven by passion. The thoughts of scientists, researchers and other health-related experts will frequently grace these pages, but Salon will also lure contributors who are not always part of the world of health and medicine, people such as an eco-farmer or a yoga master, who can make a worthwhile contribution to the discourse on health in the spirit of our transdisciplinary world. The aim is to introduce novel ideas into health and medicine.

This page will offer a lively mélange of thoughtful and sometimes quirky ideas that will ignite sparks of insight and stimulate thought and discussion. Our hope is that the conversational nar-

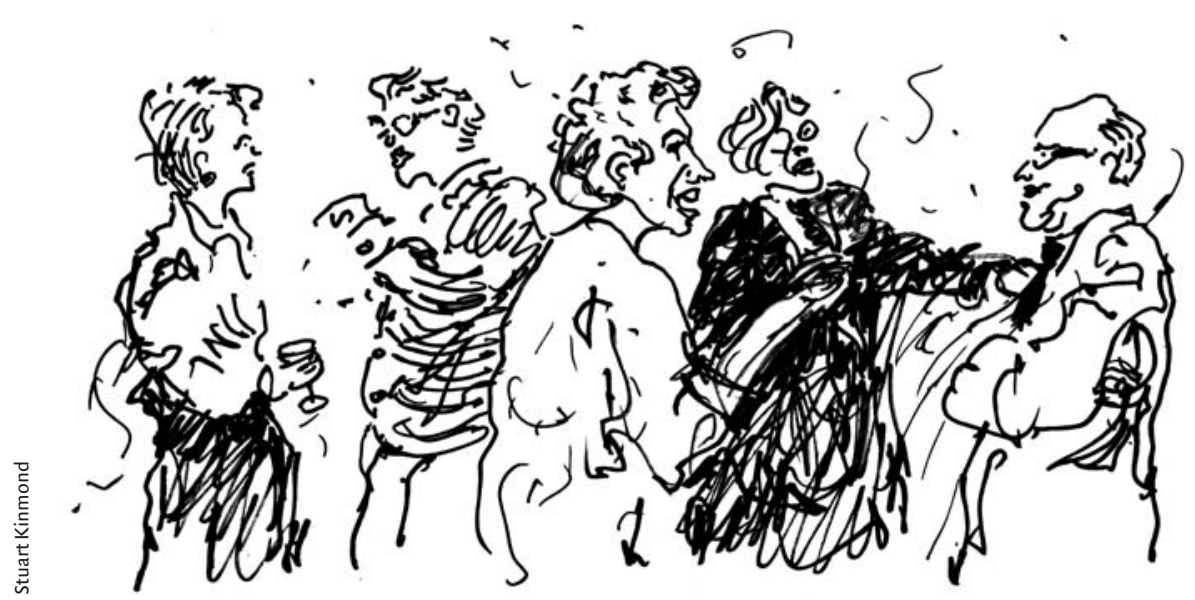

ratives in CMAJ Salon will become fodder for engaging stories that one offers at parties or in staff rooms.

One churlish definition contends that salons are a combination of a watering hole plus bookish thugs. Sadly, we cannot offer the former, but we hope to avoid the latter. Off the printed page, the heart of the salon experience - the interchange of ideas - will begin in earnest at cmaj.ca, where readers can post their thoughts on the articles. This intellectual e-exchange, open to all in an atmosphere of politeness and respect for others, will provide a way out of the cul de sac of elitism associated with salons.

Historically, salons were hosted by titled or wealthy women and later, in the 2oth century, by gifted, intelligent women with a facility for stimulating conversation. I will endeavour to fulfill the role as a quiet, behind-the-scenes editor and, perhaps, in the best-case scenario, muse. I have big shoes to fill. Gertrude Stein hosted Saturday evening salons in Paris beginning in I907 for luminaries such as Ernest Hemingway, Pablo Picasso, Henri Matisse and Guillame Apollinaire. Hosting is a serious business and not al- ways risk free: Madame Anne Louise Germaine de Staël, a well-known hostess of a philosophy-based salon in the late I8th and early igth centuries, was exiled from Paris by Napoleon Bonaparte. I don't particularly aspire to life in the wilds of Renfrew County, but then again an e-letter from Stephen Harper would be amusing.

Above all else, as readers, writers or e-participants, CMAJ Salon is your page. Welcome, and as Stein reportedly said when greeting callers at her salon, "Entrez-vous."

\section{Barbara Sibbald BJ}

CMAJ Deputy Editor, News and Humanities

The author wishes to thank the journalists and editors, in particular Dr. Dorian Deshauer, who helped develop the CMAJ Salon concept.

Contributors are encouraged to send their discourse (700 words maximum, French or English language) to salon@cma.ca. See contributors guidelines at cmaj.ca. 